\title{
ЗНАКИ ПРОШЛЫХ ЭПОХ: ИСТОРИЗМЫ И АРХАИЗМЫ НА ЗАНЯТИЯХ ПО РУССКОМУ ЯЗЫКУ В ИНОСТРАННОЙ АУДИТОРИИ
}

\author{
Доц. д-р Гендрик Петкевич
}

университет Vytautas Magnus

\begin{abstract}
Аннотация. Погружаясь в богатый мир русского языка и русской классической устройство, и быт, и сами люди заметно отличались от нынешних. Поэтому литературы, иностранцы часто сталкиваются неожиданными трудностями. Страницы классики, как на машине времени, переносят читателя в давние времена, когда и общественное произведения классиков воспринимаются не столь легко и просто. Сложны для понимания как особенности и приметы описываемой эпохи, так и отдельные слова, и понятия.

В статье обоснована необходимость использования лингво-методического потенциала историзмов и архаизмов на занятиях по русскому языку как иностранному. Представлень задания с использованием историзмов и архаизмов, ориентированные на формирование профессиональной компетентности иностранного студента. Цель работы с такими материалами - обеспечение качественной подготовки, повышение мотивации иностранцев к изучению русского языка, формирование профессиональных компетенций в области лингвистики, культуры речи. Автор исходит из того, что высокое качество языковой подготовки иностранных студентов является важной составляющей их профессионализма. Однако иностранные обучаюшиеся не всегда имеют представление о наџионально-культурной специифике лексического состава языка, что не позволяет им ассоциировать с лексическими единицами ту же информацию, что и носителям языка. Анализируя историзмы и архаизмы, иностранные учащиеся лучше поймут лексическую семантику слова, лингвистическую природу устаревших слов, правильно воспримут смысл и содержание художественных текстов русской классики. Приобщение к культурно-историческому и языковому прошлому народа страны изучаемого языка расширяет возможности развития языковой догадки и повышения уровня коммуникативной компетенциии иностранных студентов.
\end{abstract}

Ключевые слова: русский язык, историзмы, архаизмы, уровень коммуникативной компетенциии. 


\section{Вводная часть.}

На конкретных примерах русского языка можно понять всю абсурдность старой методологии изучения иностранного языка, строящейся только на запоминании. Бесспорно, что невозможно сформулировать, к примеру, все правила русского языка с многочисленными исключениями и их вызубрить. На это изучение ушло бы не одно десятилетие. И, если бы иностранцы начинали учить русский язык, пытаясь освоить «полную грамматику» и все «правила с исключениями» один за другим, то это был бы Сизифов труд. Не будем голословны, возьмём, например, простое русское существительное первого склонения склоняющееся по общему типу: страна, страны, страну, стране, страной, о стране, страны, стран, страны, странам, странами, о странах. Считается, что это несложно запомнить все 12 вариантов флексий? Но самое сложное начинается дальше. Например, слово граница, которое вроде бы тоже на -а уже склоняется по другому. Не границОй, а границЕй. Слово же туча кроме тучЕй вместо тучОй ещё и тучИ, а не тучЫ. Особый случай представляют такие слова как палка: палОк, а не палк, палкИ, а не палкЫ. А вот, вроде бы, тоже самое мошка, но - уже не тоже самое: мошЕк, а не мошОк. Более того, такие слова как река и рука, кажется, абсолютно должны склоняться одинаково. Ан нет: рЕками, но рукАми! Земля - земЕль (а не земль), воля - воль. Ещё хуже обстоят дела с вторым склонением, где тоже масса исключений. В итоге получается, что если посчитать реальное количество всевозможных типов склонений русских существительных, то их наберётся не менее нескольких десятков. Как это всё (а вспомним ещё о глаголах, наречиях, причастиях и деепричастиях) выучить и не перепутать, методом зубрёжки правил? Если попытаться это всё систематизировать и преподнести бедному иностранцу в качестве только «правил» - он с ума сойдёт.

Нам могут возразить: «Зачем заучивать? Необходимо приобщать к иностранному языку через коммуникацию». Понятно и общеизвестно, что только через коммуникацию можно легко достичь прогресса. В основу обучения русскому как иностранному сейчас используют коммуникативную методику, совмещая традиционные методы обучения с ситуативным и игровым, а также другими современными методиками. Процесс обучения основывается на понимании системы языка, а не на заучивании правил. А чтобы понимание перешло в навык, преподаватели используют различные уникальные системы упражнений. Студентам тогда легко дается усвоение лексики, потому что запоминание основывается на образно-ассоциативном принципе. Кажется, выход найден, но при общении иностранцы сталкиваются с подобными выражениями - «да, нет наверное...».Тут и утверждение, и отрицание, и сомнение одновременно. Вот и попробуйте объяснить, почему в итоге получается отрицание с сомнением. А фраза: «Руки не доходят посмотреть», - вообще приводит иностранцев в ступор. Причем тут руки ? И таких труднообъяснимых фраз и 
выражений великое множество. Чего стоит попросить иностранца перевести детскую фразу - «За песчаной косой лопоухий косой пал под острой косой косой бабы с косой». Судя по страницам Интернета со всевозможными роликами, можно сказать, что любимое развлечение многих людей, владеющих русским языком, - смотреть как иностранцы пытаются постичь особенности национального русского характера и языка. В одном изданий о России, каких сейчас издается множество, авторы «помогают» разобраться иностранцам с русским менталитетом и советуют студентам запомнить следующие идиомы:

- русские не преувеличивают, они «делают из мухи слона»;

- они просто талантливы или искусны в чем либо и способны «подковать блоху»;

- русский никогда не лжет, он «вешает тебе лапшу на уши»;

- русский никогда не скажет, что вы интересная личность, он скажет «у вас есть изюминка»;

- русские не перекусывают, они пытаются «заморить червячка»;

- русский не скажет, что он находится в слишком людном месте, он скажет что здесь «как сельдей в бочке»;

- русские утверждают, что этого никогда не случится - «когда лобстер (рак) на горе свистнет»;

- русский никогда не клянется в правдивости своих слов, он «дает зуб»;

- русские не хвастаются, они «пускают пьль в глаза»;

- русские не просто возбуждаются, а «выпрыгивают из итанов».

A, ещё чего стоят их выражения - «Сел в автобус. Стою», «Бори пересолила, а с солью переборщила»... Как донести (перевести) иностранцу, что «очень умныци - не всегда комплимент, умный очень - издевка, слишком умныци - угроза!» Конечно, перевод художественного текста рассматривается как особая форма функционирования языковой системы, сущность которой заключается в создании коммуникативной эквивалентности нового текста по отношению к оригиналу и по возможности передачи полного объема содержания произведения. В таких случаях только комплексный подход может обеспечить эффективность при работе над языком, при переводе с одного языка на другой, который учитывает и лингвистический, и культурологический, и исторический, и философский, и другие аспекты. Вместе с тем часто противоречие между оригиналом и переводом возникает из-за различия между культурой отправителя, к которой принадлежит оригинал, и культурой воспринимающей среды, в которой возникает перевод. Текст в такой обстановке возникает как двойное параллельное восприятие собственной и «чужой» систем взглядов на явления и предметный мир. Достоинство переводчика (да и преподавателя!) как языковой личности заключается в том, насколько искусно и точно удается сблизить два различных языка, две различные культуры. Согласно известному 
исследователю В. Гумбольдту каждый народ обведен кругом своего языка и выйти из этого круга может, только перейдя в другой. Однако такой «прорыв» представляется отчасти возможным тогда, когда мы пытаемся проникнуть в тайну «духа» другого языка [8]. Это «проникновение» невозможно без постижения русской классики, без знакомства иностранцев с русскими традициями и обычаями, особенностями поведения русских людей в разных ситуациях, ментальностью русских. Это и опредедяет актуальность темы.

Погружаясь в богатый мир русской литературы и культуры вообще, изучающий язык часто сталкивается с трудностями. Страницы классических произведений А. Пушкина, Л. Толстого, Ф. Достоевского, А. Чехова и др., как на машине времени, переносят читающего в давние времена, когда и общественное устройство, и быт, и сами люди заметно отличались от нынешних. Сложны для понимания как «особенности описываемой эпохи, ее законы и приметы, так и отдельные слова и понятия, вышедшие из обихода или изменившие свой смысл» [13]. Попробуй представить человека, одетого в зипун, шушун, кокошник, кафтан, онучи, душегрейку и т.д.; или вооруженного человека пищалью, палицей, нагайкой, булавой. Слова (историзмы и архаизмы - объект представленного исследования) можно встретить не только в художественной литературе, но и пословицах и поговорках, исторических фильмах, научных статьях, описывающих быт людей в прошлом. Всё чаще эти слова красуются (обретают вторую жизнь) и в речи современного человека. Цель статьи - продемонстрировать лингвометодический потенциал историзмов и архаизмов на занятиях по русскому как иностранному, позволяющих существенно расширить знания учащихся в лингвострановедении, сформировать умения обнаруживать отличия лексической системы русского литературного языка.

\section{Основная часть}

Лексическая система обычно привлекает наибольший интерес у тех учащихся, кто стал изучать иностранный язык. Это связано с тем, что именно в словарном фонде языка наименее опосредованно отражаются изменения, которые происходят в жизни общества, его культуре (материальной и духовной), политике, науке; изменения в системе коллективных и даже индивидуальных ценностей. На наш взгляд, внимание изучающих в большей степени направлено на связь номинаций с реалиями, чем на внутреннюю организацию системы (уровни, иерархии, принципы и характер номинации) и ее функционирование. Однако, именно понимание внутренней организации и функциональностилистического аспектов лексической системы крайне важно как для тех, кто изучает русский язык как иностранный. Лексическое богатство студентов-иностранцев, овладевающих русским языком на профессиональном уровне, направленно развивается в течение всего времени учебы. В основном, изучается разностилевая лексика, принадлежащая к активному запасу, и это оправдано 
главной целью формирования коммуникативной компетенции. Вместе с тем очевидно, что понимание устройства лексической системы русского языка и элементарное выяснение смысла текстов невозможно без владения словами, относящимися к пассивному запасу. В данном случае мы говорим о устаревших словах и выражениях. Отметим, что для современной художественной и публицистической речи такие слова нередко оказываются элементами активного словаря (например, при исторической стилизации). Устаревшие слова, как указывалось выше, создают в произведении особый фон и настроение, указывают на явления и признаки прошлого. К примеру,

Воротился старик ко старухе,

Что ж он видит? Высокий терем.

На крыльие стоит его старуха

в дорогой собольей душегрейке,

Парчевая на маковке кичка,

Жемчуги огрузили шею,

На руках золотьле перстни,

На ногах красные сапожки.

Перед нею усердные слуги;

Она бьёт их, за чупрун таскает.

Переосмысленные устаревшие слова оказываются употребляемыми и в современной речи, делая ее эмоциональной и выразительной. Поэтому, работая с иностранцами, необходимо предлагать ряд упражнений, включающих различные способы семантизации устаревшей лексики. Напомним, что семантизация - это выявление смысла, значения языковой единицы; процесс и результат сообщения необходимых сведений о содержательной стороне языковой единицы. Методисты Л. С. Крючкова и Н. В. Мощинская выделяют десять основных способов семантизации лексики, которые используются при изучении русского языка иностранцами [10]. Рассмотрим те способы, которые можно использовать при разработке упражнений:

- Наглядность - способ семантизации слова, который предполагает обращение к иллюстративному материалу. Это лучший способ, используемый при изучении историзмов - предметов быта.

• Описание или толкование значения - классический способ семантизации, требующий обращения к толковым и переводным словарям. Студенты самостоятельно выполняют упражнения.

- Словообразовательный анализ - то есть определение того, как слово образовано и из каких морфем. Можно использовать этот способ, сравнивая структуру таких слов, как почитать (устаревшее) - считать (соврем.), отсторонить (устаревшее) - отстранить (соврем.). Словообразовательный анализ необходим для определения внутренней формы устаревшего слова, например: башмачник - тот, 
кто делает башмаки (и в словаре можно смотреть слово башмак, а не башмачник).

- Учет контекста - мы понимаем, что слова запоминаются не как составляющие словаря, а как фрагменты высказывания. Иногда слова становятся семантическими архаизмами или семантическими историзмами, и только контекст позволяет выявить устаревание значения. Например, в статье И. С. Тургенева «По поводу “Отцов и детей”» встречается предложение: Я брал морские ванны в Вентноре, маленьком городке на острове Уайте... Глагол брать не употребляется сегодня в выражении брать ванны, то есть контекст позволяет увидеть архаичность выражения.

- Подбор синонимов - считается, что способ особенно уместен для объяснения слов художественного стиля речи.

- Перевод - обычно используется для выяснения значения абстрактной лексики. Но при изучении устаревших слов в художественных текстах он выполняет дополнительную функцию - выявления специфики художественного перевода. Так, одно из предлагаемых заданий - сравнить фрагменты какого-то произведения с их переводами на родной язык. Исследователи Л. С. Крючкова и Н. В. Мощинская считают, что не надо часто прибегать к переводу при изучении лексики иностранного языка, так как этот способ требует минимальных интеллектуальных усилий учащихся.

В методике преподавания иностранных языков существует и принцип беспереводности, «исключающий использование родного языка в системе обучения иностранному языку». Беспереводная семантизация (наглядность, раскрытие внутренней формы слова, подбор синонимов и антонимов и др.), в соответствии с данным принципом обучения, имеет преимущества перед переводом. Разработанные в современной дидактике упражнения, которые мы используем в работе с группами литовских студентов, изучающих английский и русский языки, направлены на развитие словарного запаса учащихся, формирование понимания системных связей в лексической системе русского языка, закрепление формирование лингвокультурологичной компетенции:

Перед Вами существительные - названия профессий. Лекарь, ямщчик, бурлак, кучер, хожальій, башмачник. Задания:

1) Определите по словарям лексическое значение этих существительных.

2) Укажите, используются ли эти слова сегодня.

3) Если слова не используются, то по каким причинам? Сгруппируйте слова в зависимости от причин ухода из русского языка. Как называются такие слова? 
В русском языке XIX в. были такие названия лиц по социальному положению: Барыня - помещица, богатая женщина. Приживалка - бедная женщина, не из крепостных, жившая в барском, помещичьем или купеческом доме на средства хозяев, не имевшая никаких определенных обязанностей и развлекавшая хозяйку, составлявшая ее общество Девка - крестьянская девушка. Задания:

В каких значениях эти слова используются сегодня? Они имеют положительную или отрицательную окраску? Как Вы думаете, почему?

Проанализируйте выделенные в предложениях формы слов. Дайте им исторический комментарий: современные / устаревшие, в чем именно заключается устарелость. Замените устаревшие формы на современные:

1) ...я должен сознаться, что никогда не покушался «создавать образ», если не имел исходною точкою не идею, а живое лицо, к которому постепенно примешивались и прикладывались подходящие элементы. Не обладая большою долею свободной изобретательности, я всегда нуждался в данной почве, по которой я бы мог твердо ступать ногами (И.С. Тургенев).

2) ...воспроизвести истину, реальность жизни - есть высочайтее счастие для литератора, даже если эта истина не совпадает с его собственными симпатиями ( И.С. Тургенев)

3) Я постараюсь его избегнуть (И.С. Тургенев)

4) ...мне хотелось в предисловии к этому сочинению изложить мой взгляд на него и тем предупредить те недоумения, которые могут возникнуть в читателях (Л.Н. Толстой).

5) ...вывод о деятельности таких-то и таких-то войск, который позволяет себе делать историк, оказывается противуположным выводу художника (Л.Н. Толстой).

6) Наполеон привез с собой фальшивьх ассигнаций (Л.Н. Толстой)

$>$ В статье И.С. Тургенева «По поводу “Отцов и детей”» есть предложение: Я брал морские ванны в Вентноре, маленьком городке на острове Уай$m e .$. В каком значении употреблен глагол брать - прямом или переносном? Сегодня не говорят: брать ванну. Какое устойчивое выражение с другим глаголом используется?

В русской речи много устойчивых выражений со словом Бог. Объясните значение таких выражений в примерах из повести «Кавказский пленник» Л.Н. Толстого:

1) Приезжай со мной проститься, похорони, а там и с богом поезжай опять на службу.

2) Бог даст - и сам выберусь.

3) Ну, пронёс бог; вставай, пойдём. 
4) Не могу, ей-богу, не могу; сил моих нет.

5) А сам думает: «Избави бог тут, в чистом поле, увидит конный татарин: хоть близко

C богом - выражение пожелания, напутствие. Бог дасm - выражение надежды на благополучный исход дела. Бог пронес - выражение, сообщающее, что удалось избежать опасности, неприятности, устранить беду. Ей-богу - выражение для подтверждения чего-либо, уверения в чём-либо, «в самом деле, действительно». Избави бог - выражение нежелательности свершения чего либо, беспокойство по поводу осуществления чего-либо.

История русского речевого этикета:

1) В XIX веке были такие обращения к собеседнику: Господин, cyдарь, моя почтенная. Какие из этих обращений используются сегодня? В каких ситуациях? В официальном или неофициальном общении?

2) В произведениях XIX в. в речи героев встречаются такие формы: можно-с, хорошо-с. Что выражает частица -с?

> Обратите внимание на старинные типы и названия русской одежды (лингвокультурологический комментарий преподавателя, показ иллюстраций): Армяк - старинная мужская верхняя одежда крестьян из толстого сукна в виде долгополого кафтана без сборок (изготавливался из грубой шерстяной ткани). Казакин - старинная мужская верхняя одежда в виде короткого кафтана на крючках, со сборками сзади. Кафтан - старинная мужская долгополая верхняя одежда. Сюртук - разновидность длинного (почти до колен) двубортного пиджака в талию.

> Определите, пользуясь словарями, из каких языков пришли в русский язык выделенные в предложениях слова из статей И.С. Тургенева, Л.Н. Толстого. Вспомните, каковы причины заимствования слов и выражений. Эти слова остались в языке или ушли?

1) Меня это конфузило... Огорчало.

2) Какого бы я ни был скромного мнения о своем даровании - я все-таки считал и считаю сочинение памфлета, «пасквиля», ниже его, недостойным ezo.

3) ...воспроизведенный мною... тип не успел пройти чрез постепенные фазисы, через которые обыкновенно проходят литературные типы.

4) Но через два-три дня начинают подавать реляции.

Конфузить - приводить в смущение, ставить в неловкое положение. Слово konfus пришло из немецкого языка. Лексический архаизм. Пасквиль произведение оскорбительного, клеветнического характера в публицистической или беллетристической форме. Слово pasquill пришло из немецкого язы- 
ка. Лексический архаизм. Фазис - отдельная стадия, период, этап развития, фаза. Слово phasis пришло из греческого языка. Лексико-словообразовательный архаизм. Реляции - объявление, доношение. Слово relations пришло из французского языка. Лексический историзм.

$>$ В современном русском языке есть прилагательное противный.

1) Объясните его лексическое значение, приведите синонимы.

2) В текстах XIX в. встречаем фрагменты: ....Я получал поздравления... от людей противного мне лагеря. История русской литературы со времени Пушкина не только представляет много примеров такого отступления от европейской формы, но не дает даже ни одного примера противного. Определите лексическое значение слова противный в данном контексте. Отличается ли оно от современного?

$>$ Прочитайте и переведите начало статьи Л.Н. Толстого «Бессмысленные мечтания», посвященной политическому и социальному кризису в России конца XIX в.

«17 января нынешнего 1895 г. русские представители дворянства и земства всех семидесяти с чем-то губерний и областей России собрались в Петербурге для поздравления нового, вступившего на место своего умершего отиа, молодого русского императора. За несколько месяцев до выезда представителей во всех губерниях России в продолжение нескольких месяцев или усиленные работы приготовлений для этого поздравления: собирались экстренные собрания, предлагали, избирали, интриговали; придумьвали форму верноподданнических адресов, избирали счастливцев, которые должны были ехать и иметь счастье лично передать адресы и подарки; и, наконеи, люди ехали иногда по несколько тысяч верст со всех концов России с подарками, новыми мундирами, заготовленными речами и радостными ожиданиями увидать иаря, царицу и говорить с ними. И вот все приехали, собрались, доложились, явились к министрам тому и другому, подверглись всем мыттарствам, через которые проводили их, наконец дождались торжественного дня и явились во дворец со своими подарками...»

1) Найдите устаревшие имена существительные: названия административных единиц, названия лиц, названия единиц измерения. Ответ оформите в виде таблицы: слово - значение - тип устаревшего значения.

2) В тексте есть выражение: передать адресы и подарки. Какое из слов имеет форму, неправильную сегодня?

3) Какая оценка описываемой ситуации, на Ваш взгляд, выражается в тексте - положительная или отрицательная? Какими языковыми средствами она формируется? Обоснуйте свою точку зрения.

К данным архаизмам подберите синонимы:

Книжница, коваль, кожещъ, козелок, комарник, костоватый, дадитель- 
ный, двоеникъ, двоенравие, делолюбивыцй, детенокъ, дивовище дление, днеиний, доброгласие, доброхот, доброухати.

Дополнительный материал: книгохранилищуе, библиотека, кузнеи, сумка, козленок, полог, костлявый, расточительный, близнеи, лицемерие, двуличие, трудолюбивый, ребенок, зрелище, промедление, надменность, сегодняиний, благозвучие, доброжелатель, благоухать.

> Определите, какую роль играет историзм дрожки в следующих предложениях.

«Где ваша лошадь? Чьи это дрожки? - Вот уж не угадаешь, mу dear, отвечал ей Григорий Иванович и рассказал все, что случилось.» (А. С. Пушкин «Барышня-крестьянка»)

«Фарфоровой вызолоченной чашки и не неси к нему: «Это, говорит, докторский подарок»; а ему давай пару рысаков, или дрожки, или бобер рублей в триста.» (Н. В. Гоголь «Записки сумасшедшего»)

«Разве в хороший летний день велит заложить беговые дрожки и съездит в поле на хлеба посмотреть да васильков нарвать.» (И. С. Тургенев «Два помещика»)

«Товарищ, / смотрите, / чтоб не было бед, чтоб пресса / на вас не нацъыкала. Купили бы дрожки... / велосипед...» (В. В. Маяковский «Ответ на будущие сплетни»)

$>$ Прочитайте фрагменты из художественных произведений. Найдите в них историзмы / архаизмы. Объясните их значения.

«На другой день поутру подвезена была к крыльиу дорожная кибитка; уложили в нее чемодан, погребец с чайным прибором и узлы с булками и пирогами, последними знаками домашнего баловства. Родители мои благословили меня. Батюшка сказал мне: "Прощуай, Петр. Служи верно, кому присягнешь; слушайся начальников; за их лаской не гоняйся; на службу не напрашивайся; от службы не отговаривайся; и помни пословицу: береги платье снову, а честь смолоду». Матушка в слезах наказывала мне беречь мое здоровье, а Савельичу смотреть за дитятей. Надели на меня заячий тулуп, а сверху лисью шубу. Я сел в кибитку с Савельичем и отправился в дорогу, обливаясь слезами». (А. С. Пушкин)

«Из числа всей ее челяди самым замечательным лицчом был дворник Герасим, мужчина двенадцати вершков роста, сложенный богатырем и глухонемой от рожденья. Барыня взяла его из деревни, где он жил один, в небольшой избушке, отдельно от братьев, и считался едва ли не самым исправным тягловым мужиком». (И. С. Тургенев)

«Чтоб кониы своих владений Охранять от нападений, Должен был он содержать Многочисленную рать. Воеводы не дремали, Но никак не успевали. Ждут, бывало, с юга, глядь, - Ан с востока лезет рать!» (А. С. Пушкин) 
«Вот осьмой уж день проходит, Войско в горы иарь приводит И промеж высоких гор Видит шелковый шатер. Все в безмолвии чудесном Вкруг шатра; в ущелье тесном Рать побитая лежит». (А. С. Пушкин)

«Жили-были старик со старухой. Вот и говорит старик старухе: - Поди-ка, старуха, по коробу поскреби, по сусеку помети, не наскребешь ли муки на колобок. Взяла старуха крылышко, по коробу поскребла, по сусеку помела и наскребла муки горсти две. Замесила муку на сметане, состряпала колобок, изжарила в масле и на окошко студить положила. Колобок полежал, полежал, взял да и покатился - с окна на лавку, с лавки на пол, по полу к двери, прыг через порог - да в сени, из сеней на крыльцо, с крыльца на двор, со двора за ворота, дальме и дальше». (Сказка «Колобок»)

> Подберите иллюстрации к следующим историзмам. Составьте рассказ об этих предметах: Алтын, балаган, шапка Мономаха, илем, шпага, щит.

$>$ По словарю историзмов подберите историзмы для тем: «Снаряжение русского воина», «Одежда и обувь русской женщины».

Высокое качество языковой подготовки иностранных студентов-филологов в вузах является важной составляющей их профессиональных компетенций. Как специалистам в области русского языка им необходимо знать не только систему языка и особенности общения на русском языке, но и понимать национально-культурную специфику лексического состава языка. Это позволит обучающимся ассоциировать с лексическими единицами ту же информацию, что и носители языка. Так, например, на продвинутом этапе обучения в тематической группе «Транспорт» наряду с включенными в лексические минимумы по русскому как иностранному такими словами, как автобус, трамвай, троллейбус и др. для студентов представят культурологический интерес слова-историзмы: бричка, кибитка, дрожки, дилижанс, коляска, карета, колыммага. Эти слова относятся к пассивному запасу лексики, не используются в повседневной речи, однако играют большую роль в формировании профессиональных компетенций изучающего иностранный язык, позволяющих ему интерпретировать языковые и экстралингвистические факты русского языка. Например, в современном русском языке слово колымага используется в значении с пометой «пренебрежительно». Слово коляска кроме устаревшего значения - «маленькая ручная повозка для катания детей или небольшая тележка специального назначения».Такие слова необходимы для осуществления межкультурной иноязычной профессиональной коммуникации на основе широких и глубоких лингвострановедческих знаний о социуме собеседника. Актуальность обращения к архаизмам и историзмам в иностранной аудитории имеет большое познавательное значение для обучающихся. Наблюдая за историзмами и архаизмами, изучающие русский язык как иностранный будут лучше понимать лексическую семантику слова, лингвистическую природу 
устаревших слов, не допускать ошибки в восприятии смыслового содержания и стиля исторических текстов. Несмотря на то, что многие номинируемые реалии ушли в прошлое, они остаются в пассивной памяти носителей языка и несут определенную культурную нагрузку. «Вопрос о функционировании архаичных форм в современном русском языке является актуальным. Это обусловлено тем, что язык - категория историческая, развивающаяся. В новой языковой системе закономерно сохраняются архаичные элементы - слова и словоформы эпохи прошлого. Изучение процесса архаизации важно не только как документальный фактор этнического бытия, но и как средство сохранить непрерывность культурных традиций, духовную связь поколений.

В учебную программу в нашей Академии просвещения по работе с иностранцами кроме языковых дисциплин включаются и такие дисциплины, как «География России», «Язык российских СМИ», «История и культура России», «Лингвострановедение», которые предполагают изучение русского языка в тесной связи с культурно-историческим прошлым русского народа. Обучение языку строится на междисциплинарной основе, что предполагает интеграцию знаний из различных дисциплин. Постижение исторических тем и погружение в историческое прошлое связывается с особыми ракурсами изучения русского языка, поскольку язык является бесценным историческим источником, он пробуждает прошлое, которое становится понятным из особой лингвистической и внелингвистической ткани слов, терминов, понятий, составлявших живую речь предков. Архаизмы и историзмы для студентов - это не только предмет самостоятельного изучения, но и инструмент для понимания художественного текста русской классики. В архаизмах и историзмах русского языка скрыта значимая лингвострановедческая информация, которую специалист в области русского языка извлекает в процессе чтения русскоязычных источников.

Процесс архаизации лексики является одним из наиболее ярких свидетельств динамичности языка, так как выпадение лексических единиц или отдельных значений слов из активного употребления происходит неоднократно на протяжении жизни одного поколения носителей языка. «Устаревание слов, их исчезновение - сложное явление, происходящее постепенно. Вначале устаревшее слово переходит из активного словаря в пассивный, сужается его контекстуальная сочетаемость, значение его постепенно забывается, затем данная лексема становится совсем непонятной для многих носителей языка. Этот процесс не всегда протекает прямолинейно: в ряде случаев устаревшие слова впоследствии вновь возвращаются в активный запас лексики [9, 1838 ]. Историзмы не имеют конкурирующих лексических элементов в современном языке, служат названиями реалий прошлых веков, выступают лексическим средством выразительности в художественной литературе, непосредственно отражают фрагменты картины мира русского народа, используются в научно-исторической литературе для воссоздания исторических картин разных веков, для создания колорита эпохи. Архаизм - это устарелое название акту- 
ального понятия, у которого есть другое, современное название, слово или выражение, вышедшее из повседневного употребления и потому воспринимающееся как устарелое.

Историзмы и архаизмы, не востребованные социально-образовательными условиями в современной языковой ситуации, необходимо включать в программы по русскому языку, не обедняя, таким образом, их языковую и национально-культурную составляющую.

\section{Вывод}

Одним из путей формирования и развития языковой компетенции изучающих русский язык как иностранный является разработка и использование в практике обучения специальных учебно-методических материалов, ориентированных на работу с устаревшей лексикой русского языка, направленных на увеличение словарного запаса студентов, расширение их кругозора, повышение уровня речевой культуры, привлечение внимания к лексике русского языка. В данной статье представлены материалы, ориентированные на формирование у студентов представления о месте и функциях историзмов и архаизмов в системе русского национального языка. Цель работы с такими материалами - повышение мотивации к изучению языка, формирование профессиональных компетенций в области лингвистики, культуры речи.

Выполняя представленные задания, студенты могут не только приобрести знания теоретического характера, но и сформировать умения анализировать языковой материал. Обращение к историзмам и архаизмам на занятиях по русскому языку как иностранному расширяет возможности развития языковой догадки и повышения уровня коммуникативной компетенции.. Устаревшие слова и выражения принадлежат к пласту национальноспецифичной лексики, изучение которой позволяет сформировать у учащихся понимание природы изучаемого языка. Архаизмы и историзмы обладают выраженной культурной семантикой, потому что устаревание лексических единиц всегда связано с социокультурными и политическими изменениями.

\section{Литература}

1. Аркадьева Т., Васильева М., Владимирова С. и др. Архаизмы и субстракты в русском языке // Филологические науки. Вопросы теории и практики. 2014. № 10 (40). Часть II. - С. 24-29.

2. Аркадьева Т., Кольцова Л., Кудрявцева Т. и др. Проблема описания историзмов и архаизмов в современной лексикографии // Вестник ВГУ. 2014. №3. -С.14-20.

3. Баско Н., Андреева И. Словарь устаревшей лексики к произведениям русской классики. - М.: АСТ-Пресс, 2011. - 680 с. 
4. Беловинский Л. Иллюстрированный энциклопедический историко-бытовой словарь русского народа XVIII - начало XX в. - М.: Эксмо, 2007.

5. Битехтина Н. И др. Методическая мастерская: Образцы уроков по русскому языку как иностранному. - М.: Русский язык, 2012. - 175 с.

6. Будагов Р. Истории слов в истории общества. - М.: Добросвет, 2000. $312 \mathrm{c}$.

7. Бухалов А. Устаревшая лексика как лингвистическая составляющая этнокультуроведческого подхода в обучении русскому языку // Rhema. Рема. 2012. № 1. - С. 74-83.

8. Гумбольдт В. Избранные труды по языкознанию. - М.: Прогресс, 1984. $-400 \mathrm{c}$.

9. Камаева Р. Архаизмы как одна из основных категорий устаревшей лексики // Вестник Башкирск. Ун-та. 2012. № 7. - С. 1838-1841.

10. Крючкова Л., Мощинская Н. Практическая методика обучению русскому языку как иностранному. - М., 2009. - 480 с.

11. Лесных Е. К проблеме классификации устаревшей лексики русского языка // Вестник КГУ им. Н. А. Некрасова. 2014. № 2. - С. 174-177.

12. Словарь русских историзмов / Т. Аркадьева, М. Васильева и др. М. : Высшая школа, 2005. - 305 с.

13. Федосюк Ю. Что непонятно у классиков, или Энциклопедия русского быта X1X века. - М.: Флинта, Наука, 2016. - 272 с.

14. Шанский Н. Лексикология современного русского языка. - М.: Либроком, 2013. - $312 \mathrm{c}$.

15. Щукин А. Методика преподавания русского языка как иностранного. - М.: Высшая школа, 2002. - 334 с. 


\title{
THE SIGNS OF THE PAST ERAS: EMPLOYING ARCHAIC WORDS IN THE RUSSIAN LANGUAGE LESSONS FOR FOREIGN STUDENTS
}

\author{
Assoc. Prof. Dr. Gendrik Petkevič \\ Vytautas Magnus University Education Academy
}

\section{Summary}

When diving into the rich world of the Russian language and literature, foreigners often face unexpected difficulties: from the pages of classical literature, as if in the time machine, the reader is transferred to the ancient times, when both the societal order and the people themselves markedly differed from the present times. As such, the classic works are often challenging for a contemporary reader. Difficulties in understanding arise from both the peculiarities and idiosyncrasies of the given epoch as well as individual archaic words and concepts.

The article advocates the necessity to utilize the linguistic potential of the archaic words in teaching Russian as a foreign language. The paper introduces some example tasks implementing archaisms aimed at the formation of professional competencies of foreign students. The purpose of such tasks is to provide quality training, increase the motivation of foreign students to study the Russian language, and to facilitate their adaptation of linguistic norms, both everyday and literary.

The author postulates that a high quality of language training of foreign students is an important part of their professional competencies. However, foreign students do not always have a thorough understanding of the national and cultural influences on the lexical composition of the language; it hinders their ability to associate lexical units with the same meaning as a native speaker would. By analyzing the archaic units of the language, foreign students can better understand lexical semantics and the linguistic nature of (obsolete) words, and correctly perceive the meaning and content of the Russian literary classics. Familiarizing students with a cultural, historical, and linguistic past of a country whose language is studied develops their ability to correctly construe the contextual meaning of a given text and increases their communicative competence.

Keywords: Russian language, historicism, archaisms, communicative competence. 


\section{AUTORIAUS LYDRAŠTIS}

Autoriaus vardas, pavardè: Gendrik Petkevič

Mokslo laipsnis ir vardas: humanitarinių mokslų daktaras, docentas

Darbo vieta ir pareigos: Vytauto Didžiojo universitetas, docentas

Autoriaus mokslinių interesų sritys: komparatyvistika, tautosaka

El.pašto adresas: gendrik.petkevic@vdu.lt

\section{AUTHOR'S COVER LETTER}

Author's name and surname: Gendrik Petkevič

Academic degree and name: Associate Professor, Doctor

Workplace and position: Doctor, Vytautas Magnus University Education Academy

Author's research interests: comparativistics, folklore

E-mail address: gendrik.petkevic@vdu.lt 